\title{
Influence of the Angle of Attack on the Aerothermodynamics of the Mars Science Laboratory
}

\author{
Artem A. Dyakonov ${ }^{1}$ \\ National Instutute of Aerospace, Hampton, VA, 23666 \\ Karl T. Edquist ${ }^{\S}$ and Mark Schoenenberger ${ }^{*}$ \\ NASA Langley Research Center, Hampton, VA, 23681
}

\begin{abstract}
An investigation of the effects of the incidence angle on the aerothermodynamic environments of the Mars Science Laboratory has been conducted. Flight conditions of peak heating, peak deceleration and chute deploy are selected and the effects of the angle of attack on the aerodynamics and aerothermodynamics are analyzed. The investigation found that static aerodynamics are well behaved within the considered range of incidence angles. Leeside laminar and turbulent computed heating rates decrease with incidence, despite the increase in the leeside running length. Stagnation point was found to stay on the conical flank at all angles of attack, and this is linked to the rapid flow expansion around the shoulder. Hypersonic lift to drag ratio is limited by the heating rates in the region of the windside shoulder. The effects of the high angle of incidence on the dynamic aero at low Mach remains to be determined. Influence of the angle of attack on the smooth-wall transition parameter indicates, that higher angle of attack flight may result in delayed turbulence onset, however, a coupled analysis, involving flight trajectory simulation is necessary.
\end{abstract}

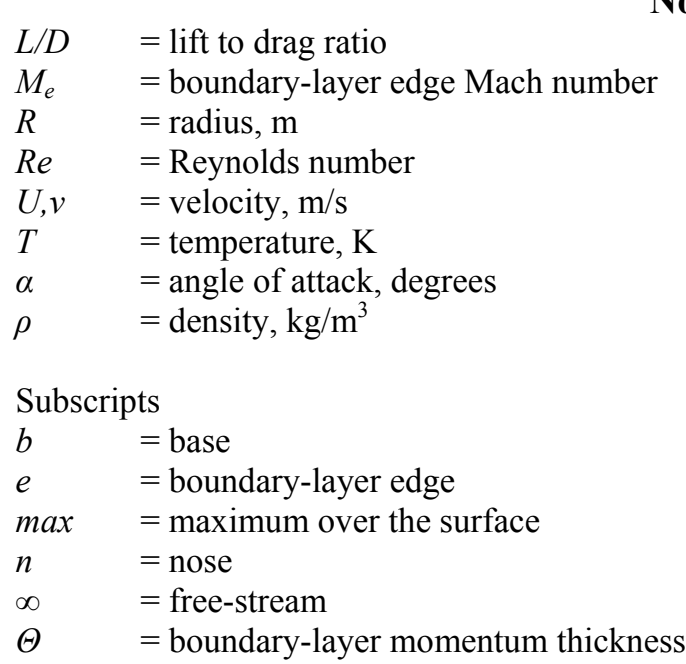

\footnotetext{
${ }^{1}$ Aerospace engineer, AIAA Member

${ }^{\S}$ Aerospace Engineer, Exploration Systems Engineering Branch, AIAA Member *Aerospace Engineer, Exploration Systems Engineering Branch, AIAA Member
} 


\section{Background}

The present analysis is a segment of a trade study to determine the range of acceptable lift to drag ratio for Mars Science Laboratory (MSL) entry. MSL is a lifting Viking-derived vehicle with a heatshield cone half-angle of 70 degrees (Figure 1). The range of acceptable incidence angles is bound by the severity of the aeroheating environment at hypersonic speeds, and the aerodynamic stability at low speeds and at parachute deploy. Since MSL, due to its large size, will encounter turbulent heating during its decent, the magnitude of the turbulent heat rates as a function of the angle of attack is evaluated. The location of the stagnation point and the peak laminar heating is determined for angles of attack between 10 and 26 degrees. It is found that for most of the conditions, considered in this analysis, the stagnation region remains on the cone flank and does not migrate to the shoulder of the vehicle. This is especially important during the high heating segment of the entry, as the movement of the stagnation point to the shoulder may result in the augmentation of the shoulder heating beyond the thermal protection system (TPS) capability. The physical phenomenon that occurs at high hypersonic conditions and limits the location of the stagnation region to the cone flank even for the incidence angles greater then 20 degrees is found to be a consequence of the sonic line location on blunt cones with small shoulder radius.

The present analysis indicates that predicted laminar and turbulent heating over most of the surface of the vehicle decrease with the increase in incidence within the considered range. The heat rate at the windside shoulder increases, as could be expected, and, for some conditions exceeds the heating over the rest of the vehicle.

The peak predicted value of the smooth wall transition parameter $\mathrm{Re}_{\theta} / \mathrm{M}_{\mathrm{e}}$ over the surface is found to decrease with the increase in incidence. Based upon the completed CFD it may be possible to develop a

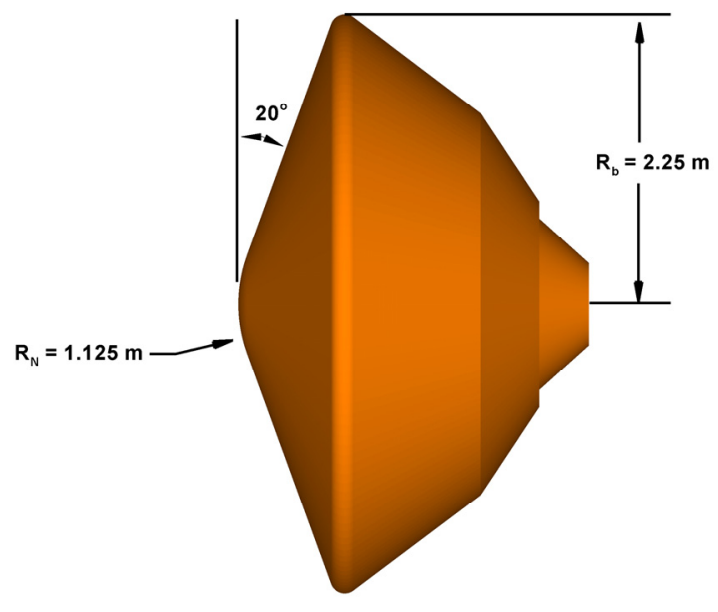
relation between the length of the turbulent heat pulse and the trim angle of attack. While the present data indicates that the incidence increase may reduce the duration of the turbulent heating, a higher fidelity analysis is required. Analysis of the effect of the angle of incidence on the length of the turbulent heating pulse would require a flight simulation to properly construct the new trajectory, since the higher L/D vehicle will generally fly along a different trajectory, then that of a lower L/D vehicle.

The principle objective of this analysis was to determine the maximum acceptable L/D for MSL. One of the concerns is the behavior of the static aero at incidence angles beyond 16 degrees. As the present investigation indicates, the static aero at the peak heating, peak deceleration and parachute deploy flight conditions are very nearly linear between 10 and 26 degrees incidence and do not limit the selection of L/D for the mission. 


\section{A. Computational Method}

\section{Aerothermal environments}

Aerothermal environments were calculated using LAURA program ${ }^{1,2}$. This program is a parallel multiblock code that is extensively used in entry vehicle calculations. The code can solve Euler, full NavierStokes and Thin Layer Navier-Stokes flow-fields using an upwind point- and line-implicit relaxation. In the present analysis the solutions of the reacting Thin Layer Navier-Stokes equations are employed. Fully turbulent solutions were also calculated using Baldwin-Lomax algebraic turbulence model. The gas (eight specie model: $\mathrm{CO} 2, \mathrm{CO}, \mathrm{C}, \mathrm{N} 2, \mathrm{~N}, \mathrm{NO}, \mathrm{N} 2, \mathrm{O} 2, \mathrm{O}$ ) is assumed to be in thermo-chemical non-equilibrium. The wall catalysis is enforced by requiring recombination of $\mathrm{CO} 2$ at the vehicle's surface. This condition is presently used in the aeroheating analysis to correlate the test data. The heating rates are calculated at radiative equilibrium wall temperature.

Two conditions, selected for these calculations represent the peak heating/peak deceleration region of the 0517 peak heat rate MSL trajectory. At the peak heating point, which occurs at around Mach 23.4 flight, the laminar solutions at 10,18 and 26 degrees incidence illustrate general trends. A more detailed analysis of the influence of the angle of attack on hypersonic aerothermodynamics is developed at Mach 16 flight condition. At Mach 16 laminar solutions are calculated between 10 and 26 degree incidence in 2 degree increments. Turbulent solutions are also computed at several angles of attack.

In determining the aerodynamic heating of Viking-derived shapes it is common to calculate the forebody flow fields separately because the flow over the shoulder is supersonic for all typical combinations of incidence and the free stream Mach for which aeroheating is important. This makes it possible to decouple the forebody flow from the wake-flow. Since the boundary layer edge Mach number on the wind-side shoulder decreases with the increase in alpha, it is important to verify that the forebody decoupling is permissible for the range of alpha considered in this analysis.

\section{B. Influence of Incidence on Computed Heatrates}

Figure 2 and Figure 3 show the variation of boundary layer edge Mach number in the vehicle's pitch plane. Wind-side and leeside shoulders of the vehicle are on the left and right sides of the plots respectively. The figures demonstrate that the shoulder flow is supersonic for all incidence angles at Mach 23.4 and 16. Forebody flow is, therefore, free from the influence of the wake at these conditions, and can be calculated separately.

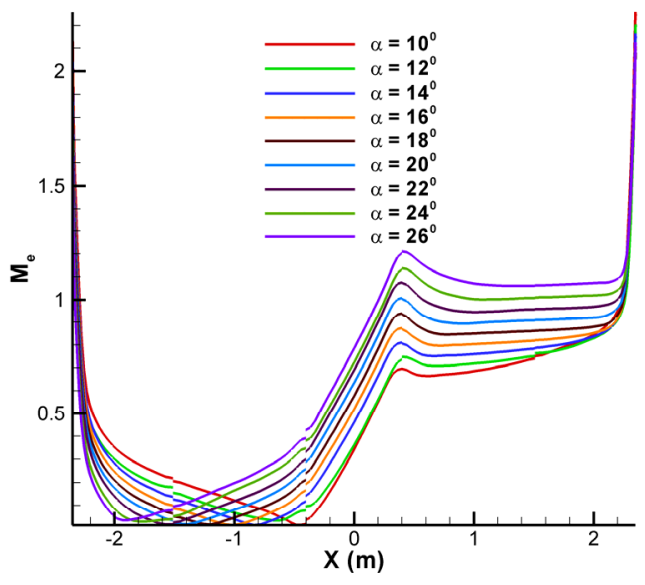

Figure 2. Pitch plane $M_{e}\left(M_{\infty}=16\right)$

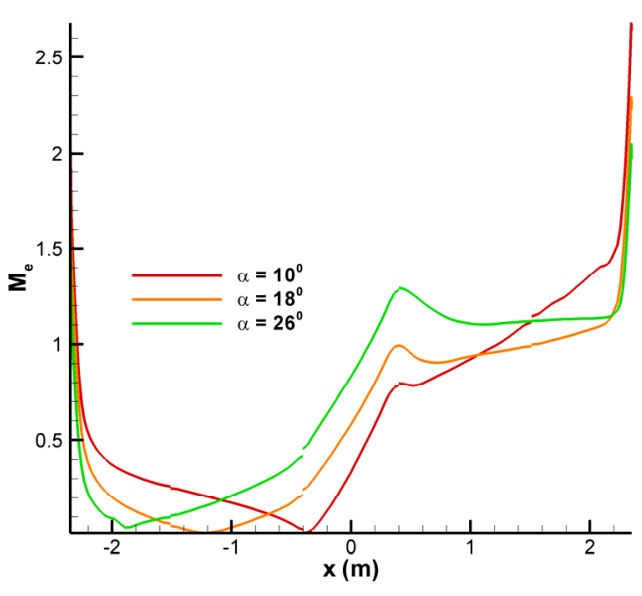

Figure 3. Pitch plane $M_{e}\left(M_{\infty}=23.4\right)$ 
The influence of the vehicle incidence angle on the laminar heat rates and their distributions is shown in the Figures 4 and 5. The wind-side shoulder heating increases with alpha, while the heating over most of the rest of the forebody decreases. Interestingly, similar trend exists in the turbulent heating distribution

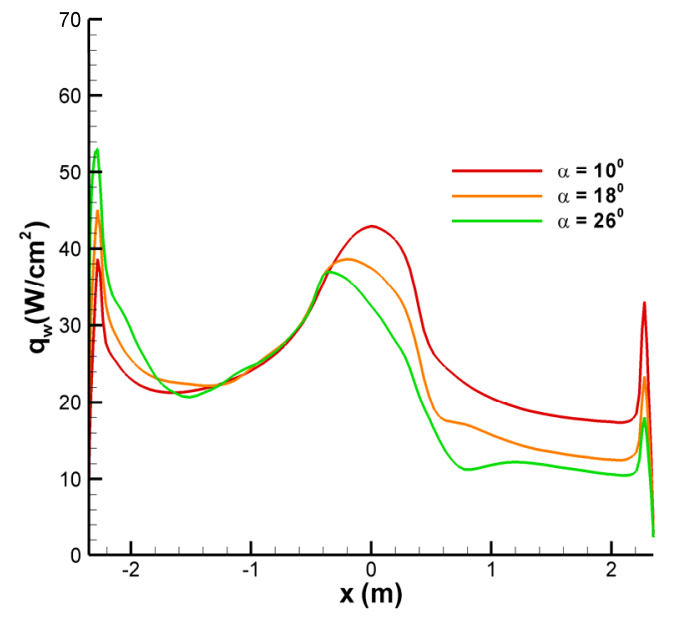

Figure 4. Mach 23.4 LAURA laminar heat rates

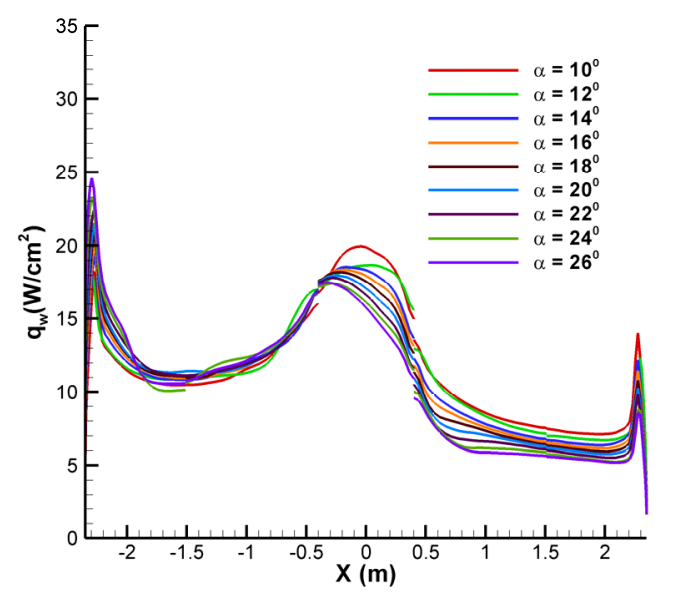

Figure 5. Mach 16 LAURA laminar heat rates

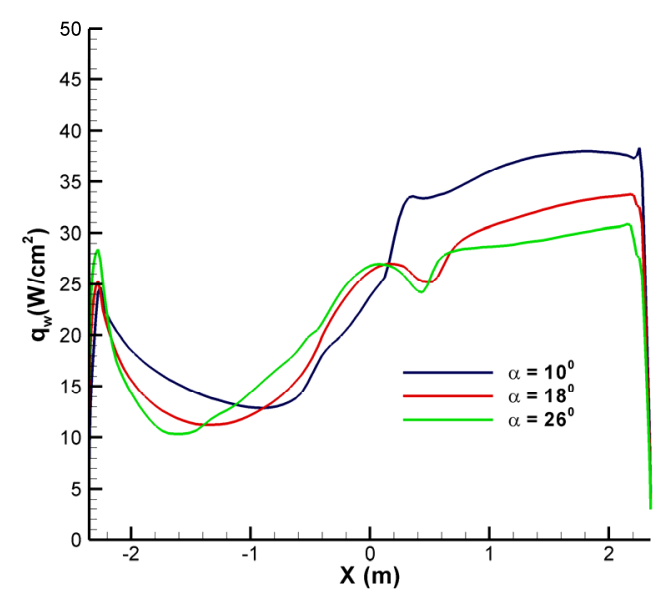

Figure 6. Mach 16 LAURA turbulent heat rates
(Figure 6). Turbulent heating levels over most of the body decrease with increasing incidence, despite the increase in the leeside surface streamline running length. Solutions at higher incidence angles indicate that the wind-side shoulder heating may exceed leeside flank heating. The leeside flank heating rates presently determine TPS sizing, and this is acceptable for moderate angles of attack.

\section{Effect of the Incidence on Surface Pressures}

Variation of the surface pressure in the plane of symmetry as a function of the angle of attack is shown in the Figure 7. Increase in incidence angle moves the center of pressure away from the centerline of the vehicle, which may result in lower compressive forebody deformations. It is expected that MSL will experience static aeroelastic deformations, which, depending on their scale, may attribute to changes in the aerodynamics. Unlike most of its predecessors, which had flown nonlifting trajectories at incidence angles near zero, MSL is an actively guided lifting vehicle, and the trim characteristics are an important part of the its aerodynamic performance. Due to the precision landing requirement ${ }^{3}, \mathrm{MSL}$ is particularly sensitive to factors, such as the aeroshell deformations, which introduce aerodynamic uncertainties during flight. While the present approach is to design the forebody such as to minimize deformations altogether, it may be advantageous to investigate high incidence operation as a possible way to reduce deformations for the future missions of this class.

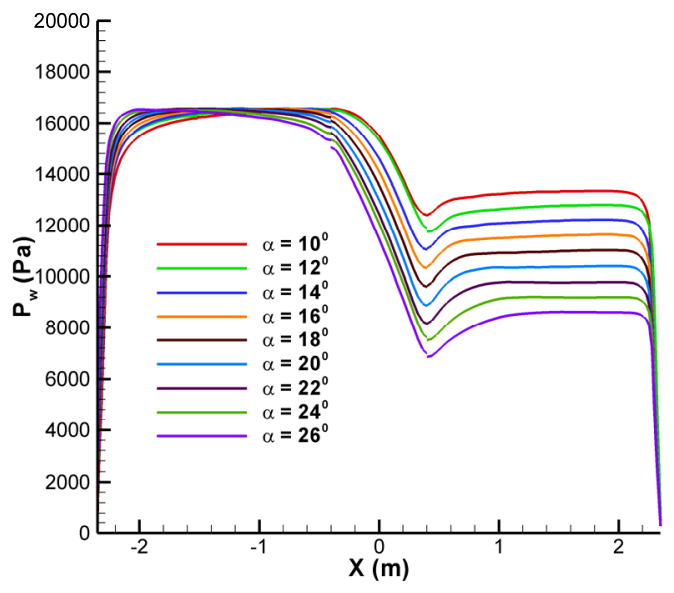

Figure 7. Mach 16 pitch plane surface pressures 


\section{Stagnation point movement}

It was believed that the increase in incidence angle past the cone half angle will result in the stagnation point movement to the shoulder of the vehicle and aggravation of the vehicle's aerothermal environment. We find that, at hypersonic regimes the stagnation point stays on the cone, does not transition to the shoulder, and its movement along the cone originator is very nearly linear with respect to the angle of attack as its varied over the range, considered herein. The variation of the wall shearing stress in the vehicle's plane of symmetry (Figures 8,9 and 10) illustrates the motion of the stagnation region as the incidence angle is varied.

Due to the small shoulder radius, windside shoulder flow is mostly supersonic for all cases, indicating that the flow stagnation will occur on the cone flank for a wide range of incidence angles. While the shear stress distribution may suggest asymptotic behavior this is not so. The flow will stagnate on the shoulder once the incidence angle, sufficient to move the sonic line further off the cone is reached, but the incidence angle required for this to occur is outside the interrogated range (Figure 11).

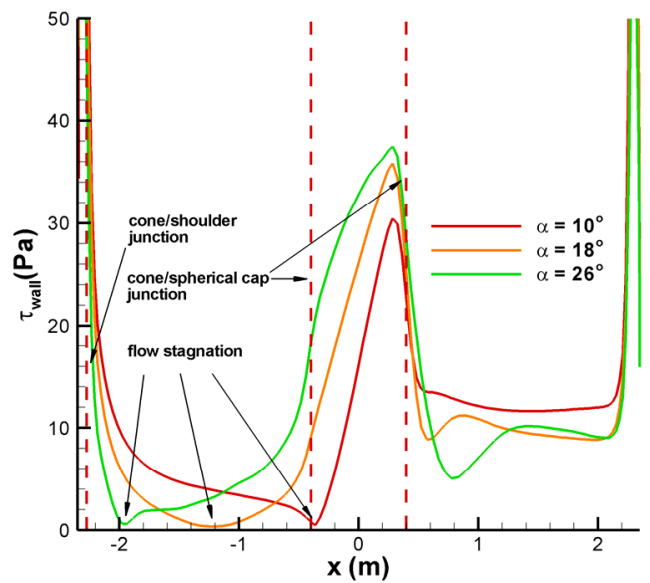

Figure 8. Pitch plane shear, Mach 23.4

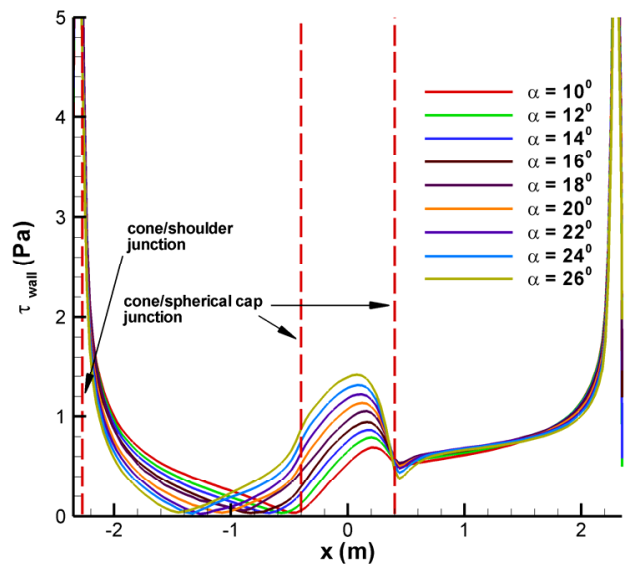

Figure 10. Pitch plane shear, Mach 2

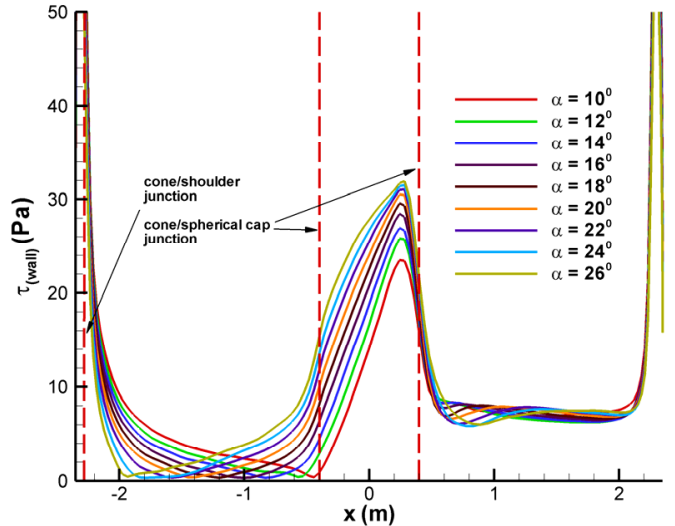

Figure 9. Pitch plane shear, Mach 16

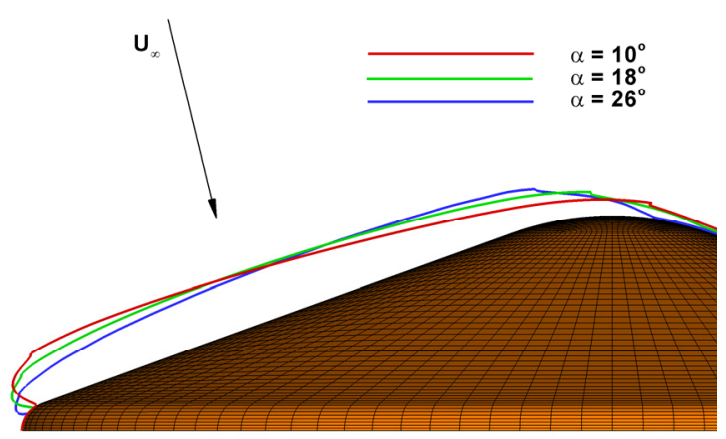

Figure 11. Influence of incidence angle on the sonic line, Mach 23.4 


\section{Influence of angle of attack on turbulent transition}

Because of the aeroshell size and the ballistic coefficient, MSL is going to experience turbulent heating during entry ${ }^{4}$. An experimental program, involving LaRC Mach 6 Air tunnel, CUBRC LENS and GALCIT T5 facilities has been under way to bound turbulent augmentation and to determine the onset of transition ${ }^{5}$. While MSL is being designed for a fully turbulent heat pulse, better understanding of the length of the actual turbulent heat pulse and the effects of the angle of attack on turbulent heating is desirable.

To determine the onset of turbulence and the likely length of the turbulent heat pulse a set of laminar solutions along the trajectory is computed, as outlined in the Table 1. Angle of attack for these solutions was constant and equal 13 degrees. Laminar solutions yield the peak values over the surface of the transition parameter at each condition. It should be pointed out, that the values of the maximum $R_{\theta} / \mathrm{M}_{\mathrm{e}}$ over the surface are approximate in the sense that they are estimated from the CFD. A number of numerical and user uncertainties feed into this, such as the calculation of the momentum thickness and boundary layer thickness by the code, and determining the proper location of the maximum $\mathrm{Re}_{\theta} / \mathrm{M}_{\mathrm{e}}$ by the analyst.

Table 1. Conditions along 0517 peak heat rate trajectory

\begin{tabular}{ccccc}
\hline \hline $\begin{array}{c}\text { Time } \\
(\mathrm{sec})\end{array}$ & $\begin{array}{c}\text { Altitude } \\
(\mathrm{m})\end{array}$ & $\begin{array}{c}\mathrm{U} \mathrm{U}_{\infty} \\
(\mathrm{m} / \mathrm{s})\end{array}$ & $\begin{array}{c}\rho_{\infty} \\
\left(\mathrm{kg} / \mathrm{m}^{3}\right)\end{array}$ & $\begin{array}{c}\mathrm{T}_{\infty} \\
(\mathrm{K})\end{array}$ \\
\hline 668 & $5.126 \mathrm{E}+04$ & $5.521 \mathrm{E}+03$ & $3.004 \mathrm{E}-05$ & 137.3 \\
686 & $3.412 \mathrm{E}+04$ & $5.242 \mathrm{E}+03$ & $2.671 \mathrm{E}-04$ & 160.4 \\
695 & $2.692 \mathrm{E}+04$ & $4.766 \mathrm{E}+03$ & $6.833 \mathrm{E}-04$ & 170.4 \\
703 & $2.212 \mathrm{E}+04$ & $4.089 \mathrm{E}+03$ & $1.139 \mathrm{E}-03$ & 175.3 \\
717 & $1.833 \mathrm{E}+04$ & $2.861 \mathrm{E}+03$ & $1.968 \mathrm{E}-03$ & 180.6 \\
727 & $1.727 \mathrm{E}+04$ & $2.230 \mathrm{E}+03$ & $2.216 \mathrm{E}-03$ & 181.9 \\
746 & $1.601 \mathrm{E}+04$ & $1.545 \mathrm{E}+03$ & $2.229 \mathrm{E}-03$ & 182.5 \\
840 & $9.263 \mathrm{E}+03$ & $5.504 \mathrm{E}+02$ & $4.026 \mathrm{E}-03$ & 189.8 \\
\hline \hline
\end{tabular}

A number of researchers believe that the turbulent transition occurs when the parameter $\mathrm{Re}_{\theta} / \mathrm{M}_{\mathrm{e}}$ reaches 300 somewhere on the surface of the vehicle. Other researchers believe that a number closer to 200 is more appropriate. We have consistently seen numbers between 350 and 550 in the tests, conducted to date 5 . The solutions, completed in this study provide some insight into the behavior of the smooth wall transition parameter $R_{\theta} / M_{e}$ at various angles of attack. Figures 13 and 14 indicate decrease of the peak $R_{\theta} / M_{e}$ with increase in angle of attack. The only deviation is the 10 degree incidence Mach 23.4 case, for which the peak $\mathrm{Re}_{\theta} / \mathrm{M}_{\mathrm{e}}$ doesn't occur at the centerline of the vehicle (Figure 15) unlike 18 and 26 degree incidence cases for the same Mach (Figures 16,17). The ten degree incidence case is the only case where we see this behavior, and it has to do with a different flow structure, with a stagnation point on the spherical cap. This case aside, it is evident that an increase in incidence tends to reduce $\mathrm{Re}_{\theta} / \mathrm{M}_{\mathrm{e}}$ over most of the vehicle. The possible consequences are the reduction of the peak turbulent heating and the delay of turbulent transition until later in the trajectory. Note that the discontinuous behavior of the parameter in the vicinity of the stagnation point (Figures 10,11 and 14) has to do with the calculation of the $\{0 / 0\}$ type indeterminacy.

It is important to note, however, that the present analysis is only a first order look at the phenomena. Typically, a higher L/D vehicle will fly a different trajectory from that of a lower L/D vehicle, hence, a more detailed study would be needed to determine the connection between the angle of attack and the transition onset. Analysis of the effect of the angle of incidence on the length of the turbulent heating pulse would require a flight simulation to properly construct the new trajectory. 


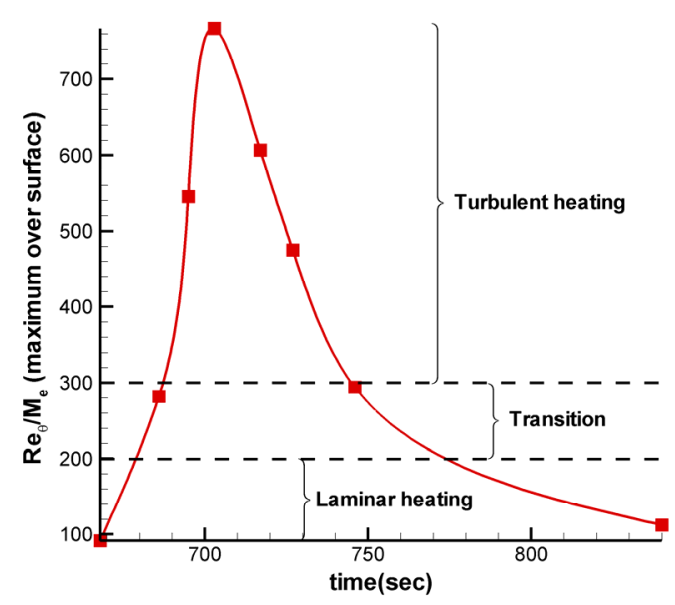

Figure 12. Peak $\operatorname{Re}_{\theta} / \mathbf{M}_{\mathrm{e}}$ during entry

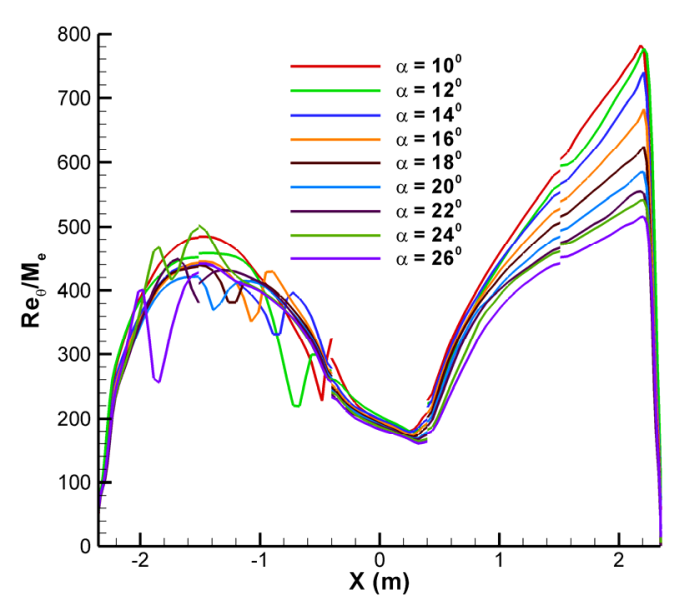

Figure 14. $\operatorname{Re}_{\theta} / M_{e}$ in plane of symmetry (Mach 16)

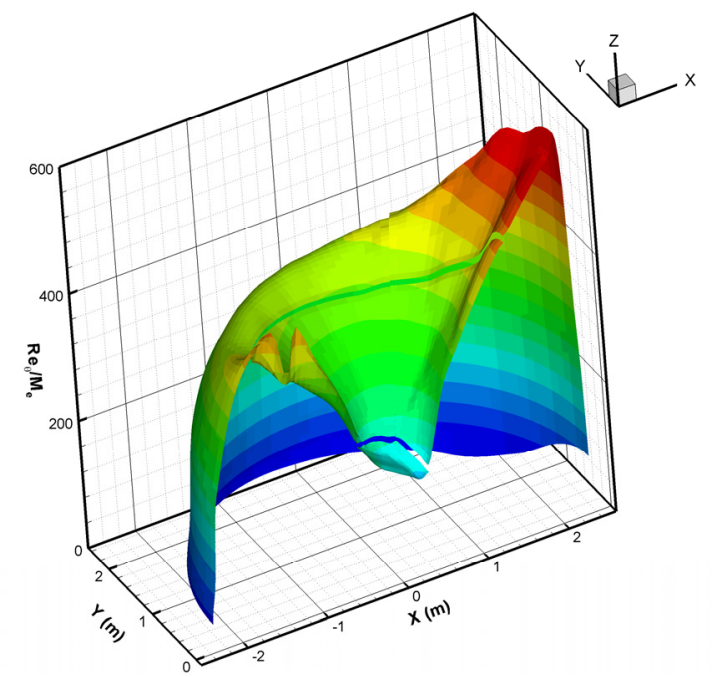

Figure 16. Mach 23.4, 18 degree incidence

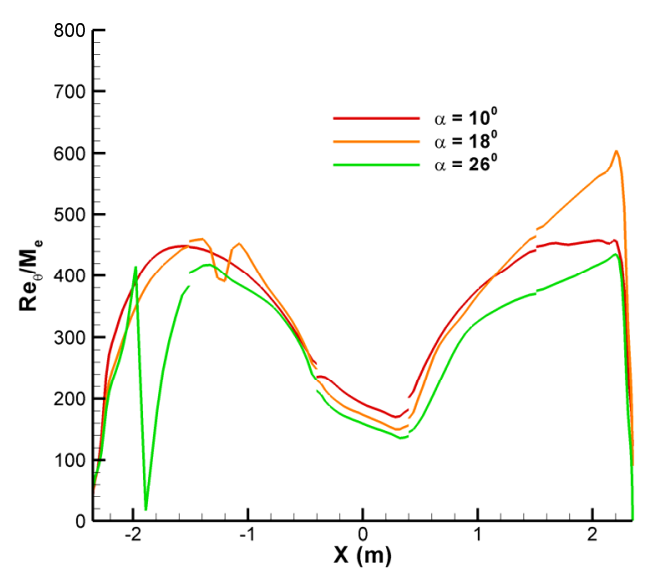

Figure 13. $\mathrm{Re}_{\theta} / \mathrm{M}_{\mathrm{e}}$ in plane of symmetry (Mach 23.4)

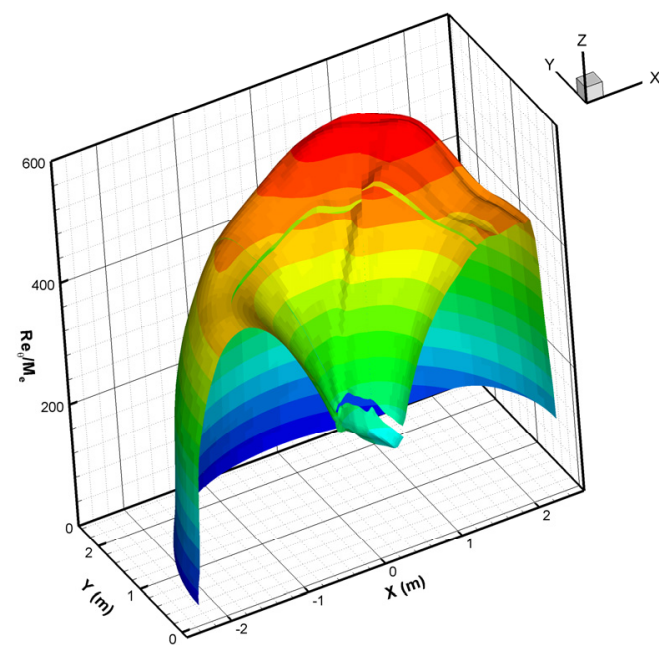

Figure 15. Mach 23.4, 10 degree incidence

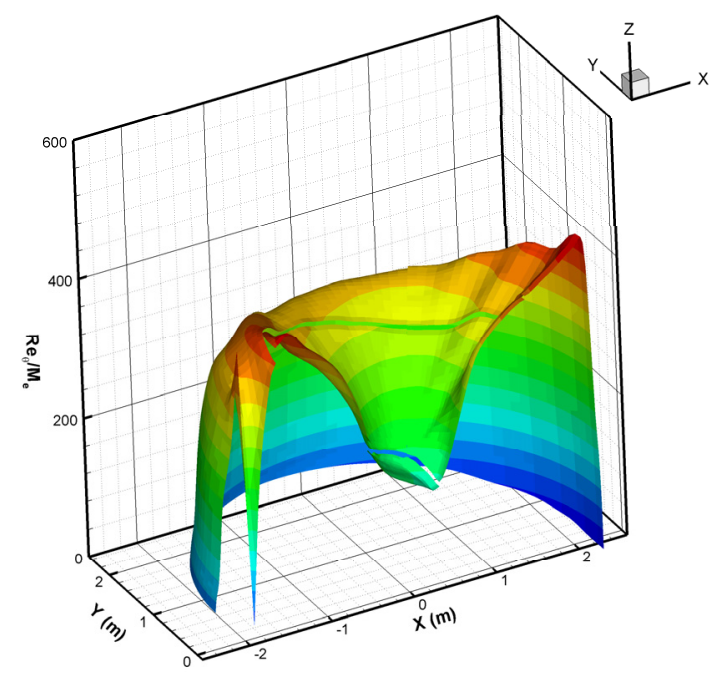

Figure 17. Mach 23.4, 26 degree incidence 


\section{Static Aerodynamics}

Hypersonic aerodynamics of Viking-derived entry vehicles are dominated by the forebody. Even at high angles of attack, when the flow on the windside of the backshell is partly attached (Figure 18) the predicted contribution of the aftbody is not significant (Table 2). The analysis of the effects of the incidence on the hypersonic aerodynamics is, therefore, carried out on the forebody only. Solutions at Mach 16 and Mach 23.4 flight conditions indicate linearity of the aerodynamics over wide range of incidence angles (Figures 18-23).

Low supersonic aerodynamics, on the other hand, could be expected to be influenced by the aftshell to a greater degree, since the aftshell contribution is a function of the type of $1 / \mathrm{M}^{2}$ (see, for example, 6) presently applied to axial force coefficient only. Recirculation region changes in size and location on the aftshell, as the angle of attack is varied. The aerodynamics of the aftshell are complex and are quite non-linear in incidence. Computed $\mathrm{M}=2$ aero for the

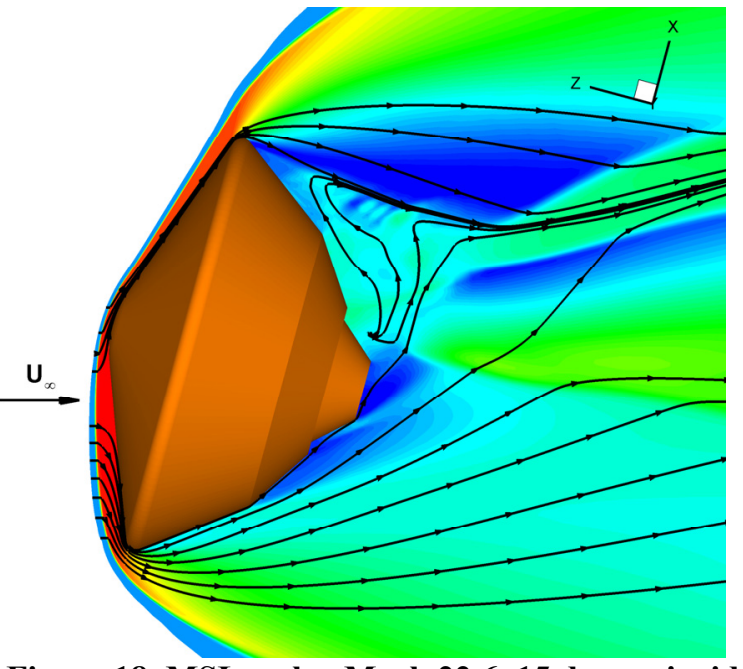

Figure 18. MSL wake, Mach 22.6, 15 degree incidence forebody only and the entire aeroshell is shown in Figures 21 and 22. We find that the predicted aftbody contribution to the pitching moment and L/D is still rather small, regardless of the incidence angle.

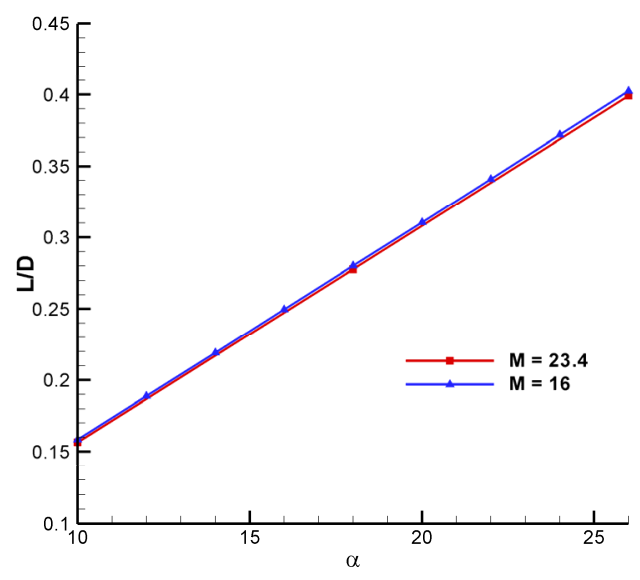

Figure 19. Hypersonic L/D

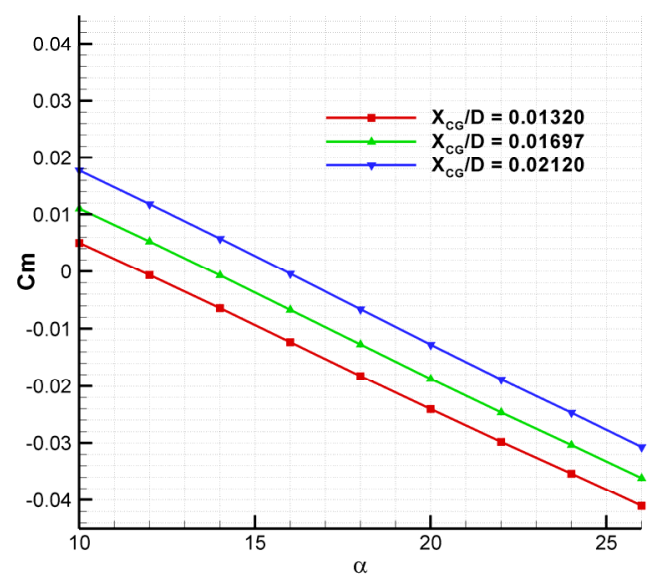

Figure 20. Hypersonic pitching moment (Mach 16, Xcg/D - radial CG offset)

Table 2. Mach 22.6 aero at 15 degrees incidence

\begin{tabular}{|c|c|c|c|}
\hline & CA & Cm & CN \\
\hline Aeroshell & 1.46 & -0.0437 & 0.0499 \\
\hline Heatshield & 1.46 & -0.0436 & 0.0491 \\
\hline Aftshell & O(E-05) & O(E-05) & O(E-04) \\
\hline
\end{tabular}




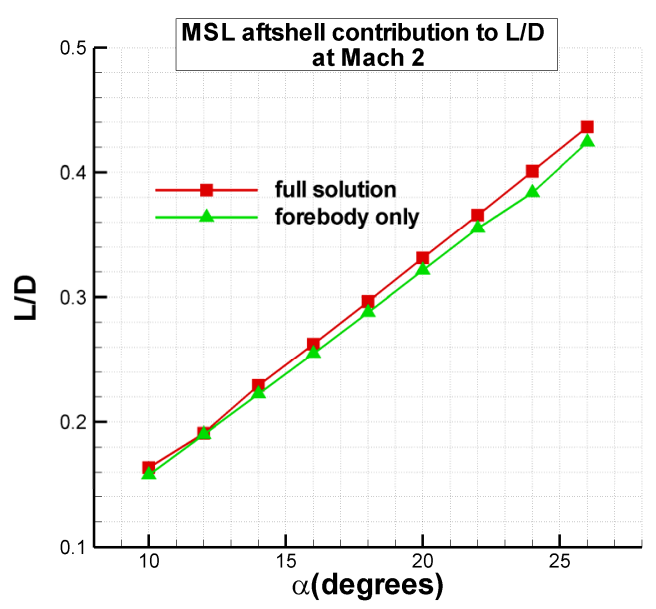

Figure 21. Supersonic L/D

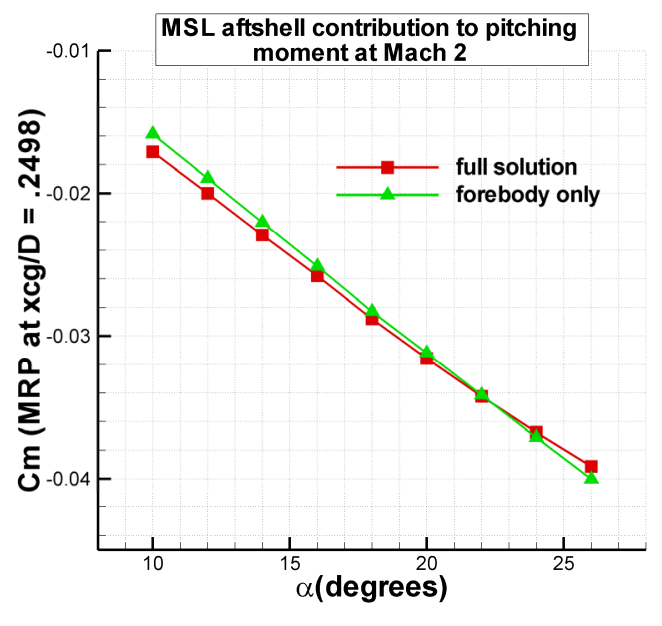

Figure 22. Supersonic pitching moment

\section{Summary and Conclusions}

The influence of the angle of attack on the aerothermodynamic environment of the Mars Science Laboratory was investigated as part of the study to bound the acceptable lift to drag ratio. Angle of attack was found to reduce both the computed laminar and turbulent heating rates over most of the heatshield while increasing the windside shoulder heating. It is found that the stagnation region stays on the conical flank despite the increase in incidence angle past the cone half-angle. This is due to the rapid flow expansion around the shoulder, which effectively limits the sonic line from moving further downstream.

No non-linearities were observed in the flow field structure over the interrogated range of the freestream conditions. Peak value of the smooth wall turbulent transition parameter $\mathrm{Re}_{\theta} / \mathrm{M}_{\mathrm{e}}$ was found to decrease with increase in incidence, despite the increase in the lee-side surface streamline running length.

The static aerodynamics are linear at both the supersonic and hypersonic Mach over the entire range of incidence angles. The computed aftshell contribution to the total aero is small, and the influence of the incidence angle on the wake doesn't significantly affect the static aero.

\section{References}

${ }^{1}$ Cheatwood, F.M., Gnoffo, P.A., "User's Manual for the Langley Aerothermodynamic Upwind Relaxation Algorithm (LAURA)", NASA TM 4674

${ }^{2}$ Gnoffo, P.A, Gupta, R. N., "Conservation Equations and Physical Models for Hypersonic Air Flows in Thermal and Chemical Nonequilibrium", NASA Technical Paper 2867, February 1989

${ }^{3}$ Lockwood, M.K., Powell, R.W., Graves, C.A., Carman, G.L.,"'Entry System Design Considerations for Mars Landers", AAS Paper 01-023, January 2001

${ }^{4}$ Edquist, K.T., Liechty, D.S., Hollis, B.R., Alter, S.J., Loomis, M.P., “Aeroheating Environments for Mars Smart Lander", AIAA Paper 2002-4505, August 2002

${ }^{5}$ Hollis, B.R., Leighty, D.S., Wright, M.J., Holden, M.S., Wadhams, T.P., MacLean, M., Dyakonov, A.A., "Transition Onset and Turbulent Heating Measurements for the Mars Science Laboratory Entry Vehicle" AIAA Paper 2005-1437, January 2005

${ }^{6}$ Schoenenberger,M., Cheatwood,F.M., Prasun,D.,"'Mars Exploration Rover Aerodynamic Database, Revision A", October 2003 